\title{
Endothelial Function and Cardiovascular Diseases in HIV Infected Patient
}

\author{
Ana Cristina O.Andrade ${ }^{1}$ and Bruno R. Cotter ${ }^{2}$
}

\author{
${ }^{1}$ Medical School of Bahia, Salvador, BA, Brazil; ${ }^{2}$ University of \\ California San Diego, California, USA
}

\begin{abstract}
The HIV epidemic has dramatically changed the paradigm for the development of drug therapy in the last 15 years. The goal is now not only to provide an effective reduction of plasma viremia, but also to reconstitute the immune deficiency due to the progression of the disease. Significant problems with the metabolism of sugars and lipids lead to the appearance of well-documented disorders such as insulin resistance, abnormalities in lipid metabolism and lipodystrophy in those patients on prolonged therapy with antiretrovirals. The question of whether or not HAART-associated lipid disorders contribute to the premature development of coronary artery disease is of major importance for the HIV community. Endothelial injury is associated with disease-related biochemical abnormalities that are implicated in HIV pathogenesis. The exploration of endothelial function began in the early 1980s at the start of the epidemic. The study of endothelial function in HIV infection and its modifications by HAART is an exciting new field in clinical research; in this review the available information on cardiovascular diseases associated with HIV infection and its treatment are discussed. Key Words: Human immunodeficiency virus, endothelial dysfunction, endothelial adhesion molecules, antiretroviral therapy, cardiovascular risk factors, atherosclerosis, coronary heart disease.
\end{abstract}

HIV epidemic has dramatic changed the paradigm for the development of drug therapy in the last 15 years [1]. Goals are not only to provide an efficacious reduction on plasma viremia, but also attempt to reconstitution of the immunodeficiency following the progression of HIV infection [2,3]. Potent enzyme inhibitors of the HIV life's cycle became available in the decade of 90's [4]. Several trials and cohort of patients receiving the combination of such inhibitors had documented a dramatic changed in the natural course of HIV infection [5-8].

Nevertheless, in the early 2000's the anticipated adverse reaction of the antiretroviral following prolonged required continuously and in interrupt of its uses, started to challenge the goals of the, highly active antiretroviral therapy (HAART) $[3,9,10]$.

Serious interaction with the metabolism of sugar and lipids lead to the appearance of well-documented disorders such as insulin resistance, abnormalities in lipid metabolism and lipodystrophy, particularly associated with protease-inhibitors [11-18]. Consequently premature coronary diseases and other cardiovascular disorder have been documented associated to the use of ARV drugs [19-21]. Despite of documentation of myocardial infarct and high rate of atherosclerosis and cardiovascular diseases in HIV infected patients associated with HAART prospective observational study reported the incidence of myocardial infarction increased, relative risk was 1.26 (95\% CI 1.12 to 1.41), directly with longer exposure with antiretroviral therapy in HIV-infected patients [22]. However, studies have shown conflicting data regarding myocardial

Received on 07 December 2005; revised 17 March 2006.

Address for correspondence: Dr. Ana Cristina O. Andrade. E-mail: anaandrade@terra.com.brE-mail :bcotter@ucsd.edu

The Brazilian Journal of Infectious Diseases 2006;10(2):139-145. (C) 2006 by The Brazilian Journal of Infectious Diseases and Contexto Publishing. All rights reserved. infarct [23-26]. It is debating the true mechanism of link between HIV, use of ARV and clinical outcome [2,27-29]. One possible mechanism it has been proposed is the cholesteryl ester accumulation in macrophages independent of dyslipidaemia. In murine model protease inhibitors are documented to up regulating CD-36 leading to the induction of atherosclerosis [30]. Others proposed mechanism are related to PIs inhibition of human proteins that are involved in lipid metabolism, including aspartyl proteases, which have homology to the catalytic site of HIV-1 protease, to which all PIs bind. One such protein is the LDL receptor-related protein (LRP), suggesting that PI-associated lipid abnormalities may be partly accounted for by reduced clearance of LRP ligands [31,32]. On the other hand, in the mouse, conditional liver-specific disruption of LRP is only associated with hyperlipidaemia after equal disruption of the LDL receptor, suggesting that LDL receptor fully compensates for the lack of LRP in these animals. Moreover, clearance of triglycerides-rich particles does not seem to be impaired in PI-treated mice [33,34].

Also it possible that, strong activation in the liver of lipogenic genes that are under the control of sterol regulatory element-binding protein (SREBP)-1c also termed as ADD1 adipocyte determination and differentiation factor 1 [35,36]. In these particular experiments, the abundance of SREBP-1c protein in the nucleus of liver cells was increased in ritonavirtreated animals [36]. This mechanism may also account for retarded degradation of apolipoprotein B-100 within the liver cells, and may thus indirectly contribute to overproduction of VLDL particles [37,38]. Microorganism are studied for their role in inducing an inflammatory response in endothelial cells (such as Chlamydia pneumoniae, cytomegalovirus, herpes simplex virus and Epstein-Barr virus), and recently HIV was documented to interact with endothelial cells membrane and to initiate inflammatory and biochemical intracellular reactions [39]. Atherosclerosis is a consequence of infection-triggered endothelial damage [40]. 
The question of whether or not HAART-associated lipid disorders contribute to the premature development of coronary artery disease is of major importance for the HIV community and this concern has been substantiated by a series of reports on PI-treated HIV-infected patients who experienced unexplained cardiovascular events [41-46]. Even though HIV infection and HAART are associated with dyslipidaemia, current data do not indicate that PIs are independently associated with an increased risk for cardiovascular morbidity and mortality $[24,47]$.

\section{Endothelial Cell Function and HIV}

It is well established that predisposing to thrombosis, leukocyte adhesion, and smooth muscle cell proliferation plays a pivotal role in the development, progression, and clinical manifestations of atherosclerosis [39,40,48-50]. Endothelium is involved in important homeostatic mechanisms of nonthrombotic vascular surfaces, vascular tone regulation and immunomodulation [39,51]. Several different clinical conditions, such as, hypertension ,dyslipidaemia diabetes mellitus, contribute to endothelial dysfunction thought to be a major link between infection, inflammation and atherosclerosis [39,51-55].

The HIV epidemic introduces a new agent that has been associated with endothelial dysfunction [56,57]. Several observations in pathophysiologic studies in humans and animals led to the formulation of the response-to-injury hypothesis of atherosclerosis, which initially proposed that endothelial denudation was the first step in atherosclerosis [52].

Injured endothelium lead to localized inflammatory response of which the direct consequence is the occurrence of occlusive thrombotic events mediated by leukocyte recruitment, platelet adhesion and aggregation, blood clotting activation and fibrinolysis derangement [40,51]. Endothelial injury is associated with disease-related biochemical abnormalities that are implicated in HIV pathogenesis. For instance, entry of virus into endothelial cells could possible occurs through $\mathrm{CD}_{4}$ antigen, galactosyl-ceramide receptors [40,51,58-60], or chemokine receptors [61-63]. Endothelial activation may also occur either by cytokines secreted in response to mononuclear or adventitial cell activation by HIV virus or by the effects of gp120 and Tat, both secreted HIV-associated proteins, on endothelium $[64,65]$.

Intercellular adhesion molecule (sICAM-1) and P-selectin are documented factors implicated in myocardial infarction and atherosclerosis [52]. High levels of this adhesion molecules represent early markers of the development of atherosclerosis $[66,67]$. Of interest, beside soluble adhesion molecules, other factors such as fibrinolytic factors, tissue plasminogen activator (t-PA) and plasminogen activator inhibitor (PAI-1) have also been considered to be markers of endothelial dysfunction [68-70].
Endothelial function begins to be explored in HIV infected patients in the early 1980s since HIV epidemic started [71-73]. Increased levels of soluble adhesion molecules was document in different stages of HIV [66,67,74,75].

HIV protease inhibitors have been successfully used against HIV infection, many metabolic side effects and premature cardiovascular diseases are often associated with this therapy [13,76-78]. In experimental model human endothelial cells treated with ritonavir showed a significant decrease in cell viability and an increase in cytotoxicity in a time- and dose-dependent fashion. Mitochondrial DNA was also substantially damaged with ritonavir treatment by long polymerase chain reaction analysis. HIV protease inhibitor ritonavir at concentrations near clinical plasma levels is able to directly cause endothelial mitochondrial DNA damage and cell death mainly through necrosis pathways but not through apoptosis [79]. Other observations with protease inhibitors alone on vascular function, was the administration of the protease inhibitor, indinavir, resulting in impaired endothelium function by measure of leg blood flow responses to intraarterial infusions of methacholine chloride, sodium nitroprusside and $\mathrm{N}^{\mathrm{G}}$-mono-methyl-L-arginine (L-NMMA). After 4 weeks of daily oral indinavir, they found that in the absence of HIV-infection, indinavir causes vascular dysfunction most likely at the level of endothelial nitric oxide production [80], and increased carotid intima thickness or atherosclerotic lesions [81].

\section{Available Methods for Assessment of Endothelial Function}

Endothelial function assessment could be performed either invasively or non invasively [82-85]. Non-invasive models include study of biomarkers that are present on the surface of endothelial cells or are expressed in response to several stimuli and have an important role in the process of leukocyte rolling, firm adhesion and transendothelial migration, biomarkers are either present on the surface of endothelial cells or are expressed in response to several stimuli and have an important role in the process of leukocyte rolling, firm adhesion and transendothelial migration $[52,66,67]$. Soluble CAMs are considered reliable biomarkers of atherosclerosis development and severity and to add to the predictive value of classic risk factors for coronary artery disease in healthy individuals and in patients [86].Another non-invasive technique is the use of ultrasonography to assess the degree of flow-mediated dilatation (FMD) of the brachial artery following an ischaemic stimulus [25,87]. Endothelial function at the brachial artery provides a surrogate measure of the coronary circulation and a correlate of the severity of coronary artery disease $[25,87,88]$. Accordingly, abnormal brachial artery endothelial function has been associated with a wide spectrum of cardiovascular risk factors, including dyslipidaemia, smoking, diabetes and hypertension [88-91]. Endothelial dysfunction is considered the key step in the development of atherosclerosis and it is 
known to be an early predictor of future cardiovascular events in patients without and with known cardiovascular disease [92-95].

Another approach to study endothelial function is to assess invasively, by studying blood flow responses, either intracoronary or intra-arterial, to infusions of metacholine chloride, sodium nitroprusside and $\mathrm{N}^{\mathrm{G}}$-mono-methyl-Larginine (L-NMMA) [91].

\section{Clinical Assessment of Endothelium in HIV Infection}

Alternatively to the invasive measurement of endothelial function derived form direct infusions of the above mentioned agents into the arteries, on can use a less invasive method of indirect assessment using the technique of post ischemic flowmediated dilation.

Stein et al. reported a cross sectional study involving 37 HIV infected patients on antiretroviral therapy (22 subjects were on protease inhibitors containing regimen and 15 were on PI-sparing regimen). They found that endothelial function was impaired in HIV infected subjects on PI-containing regimen and HIV infected patients with no ARV use had a normal FMD and they concluded that protease inhibitors are associated with atherogenic lipoprotein changes and with endothelial dysfunction [98]. Two recent studies on the effect of statins on endothelial functions and lipid profile in HIV infected patients receiving protease inhibitors, showed that pravastatin reduced concentrations of atherogenic lipoproteins and that endothelial function tended to increase in patients receiving pravastatin; however, the difference between treatment regimen was not statically significant [98100].

In order to determine the impact of HIV infection and antiretroviral therapy on markers of early vascular disease in children, Charakida et al. [101] studied 83 HIV-infected children (56 had taken HAART, of whom 31 received a regimen containing protease inhibitors; 27 were never treated and a control group of 59 healthy children). Carotid intima-media thickness (IMT) and endothelial function were measured by brachial artery flow-mediated dilatation (FMD). Children exposed to protease inhibitors had greater IMT compared with both non-PI-treated children and untreated children $(\mathrm{p}=0.02)$. FMD was also significantly reduced in HIV-infected children compared with control subjects $(\mathrm{p}=0.02)$. Comparisons of different treatment exposure groups revealed that endothelial function was impaired by a mean of $3.6 \%(95 \% \mathrm{CI}$, 1.8 to $5.3 ; \mathrm{p}<0.001$ ) for children exposed to PIs compared with untreated children and by a mean of $1.8 \%$ (95\% CI, 0.01 to 3.5; $\mathrm{p}=0.05)$ compared with non-PI-treated patients. This study demonstrates that structural and functional changes of the vasculature are already present during childhood in HIVinfected children and these changes were most pronounced in children receiving protease inhibitors, but were also observed in non-protease inhibitors treated and untreated children and the findings of the study support a role for both HIV infection itself and ART, particularly protease inhibitors, in the pathogenesis of early vascular disease, likely to be relevant to future clinical atherosclerosis [101]. Stein et al., recently, presented preliminary data from a prospective, randomized, multicenter substudy (A5152s) to evaluate the effects of antiretroviral therapy on endothelial function in treatment-naïve HIV infected individuals. Patients in the parent study, A5142, were randomly assigned to one of three antiretroviral regimens: efavirenz +2 NRTI (PI sparing regimen); lopinavir/ritonavir + 2 NRTI (NNRTI sparing regimen); and lopinavir/ritonavir + efavirenz (NRTI sparing regimen). Endothelial function determined by flow-mediated vasodilatation was measured at baseline, week 4 and at week 24. Subjects included 82 HIV infected treatment naïve patients with a median age of 34 years. Prior to starting antiretroviral therapy, FMD was impaired. After 4 weeks of treatment, FMD had significantly improved by $1.1 \%(\mathrm{p}=0.003)$ and the improvement was of similar magnitude in each arm. After 24 weeks of treatment, FMD had increased significantly by $1.9 \%$ $(\mathrm{p}<0.001)$ and it was of similar magnitude for each arm. This suggests that the use of three different antiretroviral regimens rapidly improved endothelial function in treatment naïve patients with HIV infections and that the benefits were similar regardless of antiretroviral regimen and they appeared as early as after 4 weeks and persisted at 24 weeks of treatment and they concluded that antiretroviral treatment in treatment-naïve patients improved vascular reactivity and it may decreased short term cardiovascular risks [56].

\section{Conclusions}

Endothelial dysfunction is associated with diabetes mellitus, hypertension, dyslipidemia, tobacco use and other metabolic disorders and is a predictor of future cardiovascular events. Endothelial dysfunction has also been associated with HIV infection and HIV therapy.

Protease inhibitors, a main component of antiretroviral therapy, induce many deleterious metabolic effects, such as dyslipidemia, insulin resistance and other metabolic disorders and may expose HIV infected patients to an increase risk for coronary artery disease. Antiretroviral therapy may cause endothelial dysfunction by a direct effect on the endothelial cells or by indirect mechanisms, possibly in synergy with the HIV virus on endothelial cells, or through its effects upon the lipid and glucose metabolism. However, there are still conflicting results regarding the effects of HIV infection and its therapy on endothelial dysfunction, as assessed by brachial artery flow mediated vasodilatation, some showing a worsening and others showing improvement of endothelial function (Cotter B. Endothelial dysfunction in HIV infection, In press).

The introduction of highly active antiretroviral therapy has significantly improved the prognosis of HIV infected 
patients with a dramatically reduction in both morbidity and mortality, with an improvement in patients' quality of life. However, in recent years, several clinical studies have hinted at an increased risk for cardiovascular disease (CAD), particularly among patients receiving protease inhibitors. Although the DAD Study Group found that the relative risk of cardiovascular disease increases with the duration of antiretroviral therapy, the absolute risk for cardiovascular disease remain low for most patients, except those with multiple traditional risk factors for coronary artery disease, and is far outweighed by the benefits of antiretroviral therapy in terms of reduced risks of AIDS and death in most HIV infected patients.

Traditional cardiovascular risk factors for CAD, including diabetes mellitus, hypertension, dyslipidemia, tobacco use, sedentary life style, obesity and family history need to be assessed first in HIV infected patients. In the near future, it may be possible to draw a schematic (Figure 1) showing the distribution among the general population, in levels of being either close to or far from an undesirable cardiovascular event, based on traditional risk factors for CAD; however, at this time there are no conclusive data to support HIV infection and its therapy to be considered as a definite risk factor for coronary artery disease.

Antiretroviral therapies have been considered among the miracle drugs of recent decades with a significant reduction in both mortality and morbidity and improvement in quality of life for HIV infected patients and there must be unequivocal evidence that drastic changes in antiretroviral therapy are warranted. So far, no conclusive data regarding risks for cardiovascular events support drastic changes in antiretroviral therapy. Physicians taking care of HIV infected patients should first emphasize the need for modifications of the traditional risk factors for CAD, such as smoking cessation, diet and exercise and the need to treat hypertension and other metabolic disorders, before considering changes in antiretroviral therapy.

Figure1. Hypothetical diagram of natural history of cardiovascular diseases

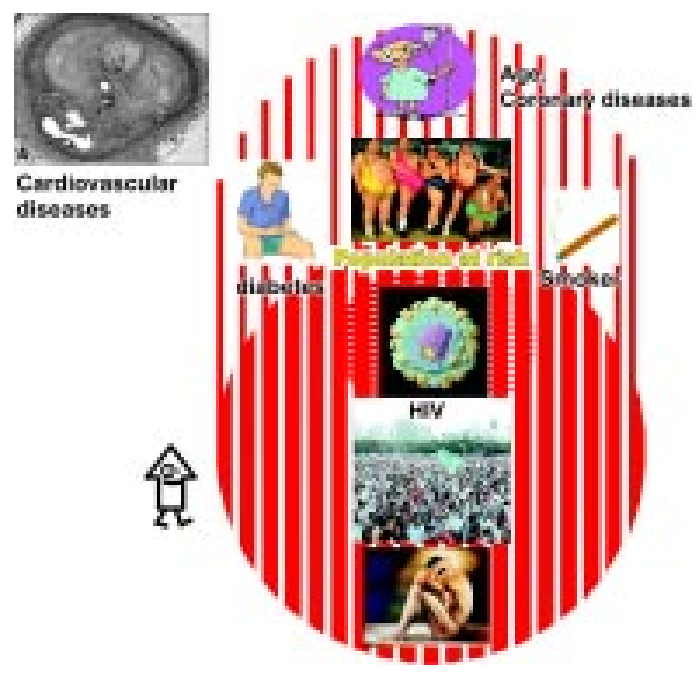

\section{Acknowledgements}

I am indebted to Dr. Roberto Badaro and Dr. Francesca Torriani for their critical review and insightful comments.

\section{Reference}

1. Fauci A.S. HIV and AIDS: 20 years of science. Nat Med 2003;9(7):839-43.

2. Nolan D., John M., Mallal S. Antiretoviral therapy and the lipodystrophy syndrome, part 2: concepts in aetiopathogenesis. Antivir Ther 2001;6(3):145-60.

3. Young B., Carmichael J.K., Johnson D., Mills T. PA update: DHHS guidelines for the treatment of HIV infection. JAAPA 2006;Suppl:3-13:3-13.

4. Wynn G.H., Zapor M.J., Smith B.H., et al. Antiretrovirals, part 1: overview, history, and focus on protease inhibitors. Psychosomatics 2004;45(3):262-70.

5. Gottlieb M.S. AIDS - past and future. N Engl J Med 2001;344(23):1788-91.

6. Palella F.J., Jr., Delaney K.M., Moorman A.C., et al. Declining morbidity and mortality among patients with advanced human immunodeficiency virus infection. HIV Outpatient Study Investigators. N Engl J Med 1998;338(13):853-60.

7. Palella F.J., Jr., Oria-Knoll M., Chmiel J.S., et al. Survival benefit of initiating antiretroviral therapy in HIV-infected persons in different $\mathrm{CD}_{4}^{+}$cell strata. Ann Intern Med 2003; 138(8):620-6.

8. Sepkowitz K.A. AIDS - the first 20 years. N Engl J Med 2001;344(23):1764-72.

9. Johnson V.A., Brun-Vezinet F., Clotet B., et al. Update of the drug resistance mutations in HIV-1: 2004. Top HIV Med 2004;12(4):119-24.

10. Wood E., Hogg R.S., Harrigan P.R., Montaner J.S. When to initiate antiretroviral therapy in HIV-1-infected adults: a review for clinicians and patients. Lancet Infect Dis 2005;5(7):407-14.

11. Bartlett J.A., DeMasi R., Quinn J., et al. Overview of the effectiveness of triple combination therapy in antiretroviralnaive HIV-1 infected adults. AIDS 2001;15(11):1369-77.

12. Christeff N., Melchior J.C., Perronne C., et al. Lipodystrophy defined by a clinical score in HIV-infected men on highly active antiretroviral therapy: correlation between dyslipidaemia and steroid hormone alterations. AIDS 1999; 13(16):2251-60.

13. Hansen B.R., Haugaard S.B., Iversen J., et al. Impact of switching antiretroviral therapy on lipodystrophy and other metabolic complications: a review. Scand J Infect Dis 2004;36(4):244-53.

14. Carr A. HIV lipodystrophy: risk factors, pathogenesis, diagnosis and management. AIDS 200317 Suppl 1:S141-S18.

15. Mallon P.W., Cooper D.A., Carr A. HIV-associated lipodystrophy. HIV Med 2001;2(3):166-73.

16. Moyle G., Carr A. HIV-associated lipodystrophy, metabolic complications, and antiretroviral toxicities. HIV Clin Trials 2002;3(1):89-98.

17. Martinez E., Blanco J.L., Arnaiz J.A., et al. Hepatotoxicity in HIV-1-infected patients receiving nevirapinecontaining antiretroviral therapy. AIDS 2001; 15(10):1261-8. 
18. Calza L., Manfredi R., Chiodo F. Dyslipidaemia associated with antiretroviral therapy in HIV-infected patients. J Antimicrob Chemother 2004;53(1):10-4.

19. Friedl A.C., Tenhofer Jost C.H., Schalcher C., et al. Acceleration of confirmed coronary artery disease among HIV-infected patients on potent antiretroviral therapy. AIDS 2000;14(17):2790-2.

20. Karmochkine M., Raguin G. Severe coronary artery disease in a young HIV-infected man with no cardiovascular risk factor who was treated with indinavir. AIDS 1998;12(18):2499.

21. Passalaris J.D., Sepkowitz K.A., Glesby M.J. Coronary artery disease and human immunodeficiency virus infection. Clin Infect Dis 2000;31(3):787-97.

22. Friis-Moller N., Sabin C.A., Weber R., et al. Combination antiretroviral therapy and the risk of myocardial infarction. N Engl J Med 2003;349(21):1993-2003.

23. Mary-Krause M., Cotte L., Simon A., et al. Increased risk of myocardial infarction with duration of protease inhibitor therapy in HIV-infected men. AIDS 2003;17(17):2479-86.

24. Klein D., Hurley L.B., Quesenberry C.P., Jr., Sidney S. Do protease inhibitors increase the risk for coronary heart disease in patients with HIV-1 infection? J Acquir Immune Defic Syndr 2002;30(5):471-7.

25. Currier J.S., Kendall M.A., Zackin R., et al. Carotid artery intima-media thickness and HIV infection: traditional risk factors overshadow impact of protease inhibitor exposure 6. AIDS 2005; 19(9):927-33.

26. Bozzette S.A., Ake C.F., Tam H.K., et al. Cardiovascular and cerebrovascular events in patients treated for human immunodeficiency virus infection. N Engl J Med 2003;348(8):702-10.

27. Holmberg S.D., Moorman A.C., Williamson J.M., et al. Protease inhibitors and cardiovascular outcomes in patients with HIV. Lancet 2002;360(9347): 1747-8.

28. Cheseaux J.J., Jotterand V., Aebi C., et al. Hyperlipidemia in HIV-infected children treated with protease inhibitors: relevance for cardiovascular diseases. J Acquir Immune Defic Syndr 2002;30(3):288-93.

29. Barbaro G. HIV infection, highly active antiretroviral therapy and the cardiovascular system. Cardiovasc Res 2003;60(1):87-95.

30. Dressman J., Kincer J., Matveev S.V., et al. HIV protease inhibitors promote atherosclerotic lesion formation independent of dyslipidemia by increasing CD36-dependent cholesteryl ester accumulation in macrophages. J Clin Invest 2003;111(3):389-97.

31. Liu N.Q., Lossinsky A.S., Popik W., et al. Human immunodeficiency virus type 1 enters brain microvascular endothelia by macropinocytosis dependent on lipid rafts and the mitogen-activated protein kinase signaling pathway. J Virol 2002;76(13):6689-700.

32. Gujuluva C., Burns A.R., Pushkarsky T., et al. HIV-1 penetrates coronary artery endothelial cells by transcytosis. Mol Med 2001;7(3):169-76.

33. Rohlmann A., Gotthardt M., Hammer R.E., Herz J. Inducible inactivation of hepatic LRP gene by cremediated recombination confirms role of LRP in clearance of chylomicron remnants. J Clin Invest 1998;101(3):689-95.
34. Lenhard J.M., Croom D.K., Weiel J.E., Winegar D.A. HIV protease inhibitors stimulate hepatic triglyceride synthesis. Arterioscler Thromb Vasc Biol 2000;20(12):2625-9.

35. Nguyen A.T., Gagnon A., Angel J.B., Sorisky A. Ritonavir increases the level of active ADD-1/SREBP-1 protein during adipogenesis. AIDS 2000; 14(16):2467-73.

36. Andre P., Groettrup M., Klenerman P., et al. An inhibitor of HIV-1 protease modulates proteasome activity, antigen presentation, and T cell responses. Proc Natl Acad Sci USA 1998; $95(22): 13120-4$.

37. Yamaguchi J., Gamble M.V., Conlon D., et al. The conversion of apoB100 low density lipoprotein/high density lipoprotein particles to apoB 100 very low density lipoproteins in response to oleic acid occurs in the endoplasmic reticulum and not in the Golgi in McA RH7777 cells. J Biol Chem 2003;278(43):42643-51.

38. Liang J.S., Distler O., Cooper D.A., et al. HIV protease inhibitors protect apolipoprotein B from degradation by the proteasome: a potential mechanism for protease inhibitor-induced hyperlipidemia. Nat Med 2001;7(12):1327-31.

39. Vallance P., Collier J., Bhagat K. Infection, inflammation, and infarction: does acute endothelial dysfunction provide a link? Lancet 1997;349(9062): 1391-2.

40. Ross R. Atherosclerosis - an inflammatory disease. N Engl J Med 1999;340(2):115-26.

41. Behrens G., Schmidt H., Meyer D., et al. Vascular complications associated with use of HIV protease inhibitors. Lancet 1998;351(9120): 1958.

42. Barthelemy O., Escaut L., Vayre F., et al. [Acute coronary syndromes in patients treated with HIV protease inhibitors]. Presse Med 2002;31(8):343-8.

43. Monsuez J.J., Gallet B., Escaut L., et al. Clinical outcome after coronary events in patients treated with HIV-protease inhibitors. Eur Heart J 2000;21(24):2079-80.

44. Gallet B., Pulik M., Genet P., et al. Vascular complications associated with use of HIV protease inhibitors. Lancet 1998;351(9120):1958-9.

45. Vittecoq D., Escaut L., Merad M., et al. Coronary heart disease in HIV-infected individuals. Adv Cardiol 2003;40:151-62.

46. Vittecoq D., Escaut L., Chironi G., et al. Coronary heart disease in HIV-infected patients in the highly active antiretroviral treatment era. AIDS 2003; 17 Suppl 1:S70-S76.

47. Depairon M., Chessex S., Sudre P., et al. Premature atherosclerosis in HIV-infected individuals-focus on protease inhibitor therapy. AIDS 2001;15(3):329-34.

48. Periard D., Telenti A., Sudre P., et al. Atherogenic dyslipidemia in HIV-infected individuals treated with protease inhibitors. The Swiss HIV Cohort Study. Circulation 1999;100(7):700-5.

49. Silvestro A., Scopacasa F., Ruocco A., et al. Inflammatory status and endothelial function in asymptomatic and symptomatic peripheral arterial disease. Vasc Med 2003;8(4):225-32.

50. Lekakis J.P., Papamichael C.M., Vemmos C.N., et al. Peripheral vascular endothelial dysfunction in patients with angina pectoris and normal coronary arteriograms. J Am Coll Cardiol 1998;31(3):541-6.

51. Verma S., Anderson T.J. Fundamentals of endothelial function for the clinical cardiologist. Circulation 2002; 105(5):546-9. 
52. Blankenberg S., Barbaux S., Tiret L. Adhesion molecules and atherosclerosis. Atherosclerosis 2003; 170(2): 191203.

53. Sondergaard E., Moller J.E., Egstrup K. Relationship between vascular dysfunction in peripheral arteries and ischemic episodes during daily life in patients with ischemic heart disease and hypercholesterolemia 4. Am Heart J 2002;144(1):108-14.

54. Tousoulis D., Charakida M., Stefanadis C. Endothelial function and inflammation in coronary artery disease. Heart 2005.

55. Blann A.D., Taberner D.A. A reliable marker of endothelial cell dysfunction: does it exist? Br J Haematol 1995;90(2):244-8.

56. Nolan D., Watts G.F., Herrmann S.E., et al. Endothelial function in HIV-infected patients receiving protease inhibitor therapy: does immune competence affect cardiovascular risk? QJM 2003;96(11):825-32.

57. Barbaro G., Klatt E.C. HIV infection and the cardiovascular system. AIDS Rev 2002;4(2):93-103.

58. Cohen O.J., Kinter A., Fauci A.S. Host factors in the pathogenesis of HIV disease. Immunol Rev 1997;159:31-48.

59. Banks W.A., Kastin A.J. Characterization of lectin-mediated brain uptake of HIV-1 GP120. J Neurosci Res 1998;54(4):522-9.

60. Banks W.A., Akerstrom V., Kastin A.J. Adsorptive endocytosis mediates the passage of HIV-1 across the blood-brain barrier: evidence for a post-internalization coreceptor. J Cell Sci 1998; 111(Pt 4):533-40.

61.Cohen O.J., Paolucci S., Bende S.M., et al. CXCR4 and CCR5 genetic polymorphisms in long-term nonprogressive human immunodeficiency virus infection: lack of association with mutations other than CCR5-Delta32. J Virol 1998;72(7):6215-7.

62.Moir S., Lapointe R., Malaspina A., et al. $\mathrm{CD}_{40}$-Mediated induction of $\mathrm{CD}_{4}$ and $\mathrm{CXCR} 4$ on $\mathrm{B}$ lymphocytes correlates with restricted susceptibility to human immunodeficiency virus type 1 infection: potential role of B lymphocytes as a viral reservoir. J Virol 1999;73(10):7972-80.

63. Ostrowski M.A., Justement S.J., Catanzaro A., et al. Expression of chemokine receptors CXCR4 and CCR5 in HIV-1-infected and uninfected individuals. J Immunol 1998; $161(6): 3195-201$.

64.Lifson J.D., Reyes G.R., McGrath M.S., et al. AIDS retrovirus induced cytopathology: giant cell formation and involvement of $\mathrm{CD}_{4}$ antigen. Science 1986;232(4754): 1123-7.

65. Stefano G.B., Salzet M., Bilfinger T.V. Long-term exposure of human blood vessels to HIV gp120, morphine, and anandamide increases endothelial adhesion of monocytes: uncoupling of nitric oxide release. J Cardiovasc Pharmacol 1998;31(6):862-8.

66. Ridker PM, Cushman M, Stampfer MJ, Tracy RP, Hennekens $\mathrm{CH}$. Plasma concentration of $\mathrm{C}$-reactive protein and risk of developing peripheral vascular disease. Circulation 1998;97(5):425-8.

67. Ridker P.M., Hennekens C.H., Roitman-Johnson B., et al. Plasma concentration of soluble intercellular adhesion molecule 1 and risks of future myocardial infarction in apparently healthy men. Lancet 1998;351(9096):88-92.

68. Ridker P.M., Vaughan D.E., Stampfer M.J., et al. Endogenous tissue-type plasminogen activator and risk of myocardial infarction. Lancet 1993;341(8854): 1165-8.
69. Tornvall P., Hamsten A., Hansson L.O., et al. Plasma C-reactive protein and lipoprotein levels, and progression of coronary artery disease after myocardial infarction treated with thrombolysis. Cardiology 2005;104(2):65-71.

70.Wiklund P.G., Nilsson L., Ardnor S.N., et al. Plasminogen activator inhibitor-1 $4 \mathrm{G} / 5 \mathrm{G}$ polymorphism and risk of stroke: replicated findings in two nested case-control studies based on independent cohorts. Stroke 2005;36(8):1661-5.

71.Teitel J.M., Shore A., McBarron J., et al. Endothelial cells modulate both T-cell-dependent and T-cell-independent plaque-forming cell generation in vitro. Int Arch Allergy Appl Immunol 1990;91(1):66-73.

72. Teitel J.M., Shore A., Read S.E., Schiavone A. Immune function of vascular endothelial cells is impaired by HIV. J Infect Dis 1989; $160(3): 551-2$.

73.Lafeuillade A., Alessi M.C., Poizot-Martin I., et al. Endothelial cell dysfunction in HIV infection. J Acquir Immune Defic Syndr 1992;5(2):127-31.

74.Puppo F., Brenci S., Scudeletti M., et al. Elevated serum levels of circulating intercellular adhesion molecule-1 in HIV infection. AIDS 1993;7(4):593-4.

75. Seigneur M., Constans J., Blann A., et al. Soluble adhesion molecules and endothelial cell damage in HIV infected patients. Thromb Haemost 1997;77(4):646-9.

76. Stein J.H. Dyslipidemia in the era of HIV protease inhibitors. Prog Cardiovasc Dis 2003;45(4):293-304.

77.Fontas E., van L.F., Sabin C.A., et al. Lipid profiles in HIVinfected patients receiving combination antiretroviral therapy: are different antiretroviral drugs associated with different lipid profiles? J Infect Dis 2004;189(6): 1056-74.

78. Barbaro G. Metabolic and cardiovascular complications of highly active antiretroviral therapy for HIV infection. Curr HIV Res 2006;4(1):79-85.

79.Zhong D.S., Lu X.H., Conklin B.S., et al. HIV protease inhibitor ritonavir induces cytotoxicity of human endothelial cells. Arterioscler Thromb Vasc Biol 2002;22(10):1560-6.

80. Shankar S.S., Dube M.P., Gorski J.C., et al. Indinavir impairs endothelial function in healthy HIV-negative men. Am Heart J 2005; 150(5):933.

81.Rhew D.C., Bernal M., Aguilar D., et al. Association between protease inhibitor use and increased cardiovascular risk in patients infected with human immunodeficiency virus: a systematic review. Clin Infect Dis 2003;37(7):959-72.

82.Corretti M.C., Plotnick G.D., Vogel R.A. Correlation of cold pressor and flow-mediated brachial artery diameter responses with the presence of coronary artery disease. Am J Cardiol 1995;75(12):783-7.

83. Corretti M.C., Plotnick G.D., Vogel R.A. The effects of age and gender on brachial artery endothelium-dependent vasoactivity are stimulus-dependent. Clin Cardiol 1995;18(8):471-6.

84.Furchgott R.F., Zawadzki J.V. The obligatory role of endothelial cells in the relaxation of arterial smooth muscle by acetylcholine. Nature 1980;288(5789):373-6.

85. Vanhoutte P.M. Endothelial control of vasomotor function: from health to coronary disease. Circ J 2003;67(7):572-5.

86.Davies M.J., Gordon J.L., Gearing A.J., et al. The expression of the adhesion molecules ICAM-1, VCAM-1, PECAM, and E-selectin in human atherosclerosis. J Pathol 1993;171(3):223-9. 
87. Adams M.R., Nakagomi A., Keech A., et al. Carotid intimamedia thickness is only weakly correlated with the extent and severity of coronary artery disease. Circulation 1995;92(8):2127-34.

88. Celermajer D.S., Sorensen K.E., Bull C., et al. Endotheliumdependent dilation in the systemic arteries of asymptomatic subjects relates to coronary risk factors and their interaction. J Am Coll Cardiol 1994;24(6): 1468-74.

89. Constans J., Marchand J.M., Conri C., et al. Asymptomatic atherosclerosis in HIV-positive patients: A case-control ultrasound study. Ann Med 1995;27(6):683-5.

90. Corretti M.C., Plotnick G.D., Vogel R.A. Smoking correlates with flow-mediated brachial artery vasoactivity but not cold pressor vasoactivity in men with coronary artery disease. Int J Card Imaging 1998; 14(1):11-7.

91.Corretti M.C., Anderson T.J., Benjamin E.J., et al. Guidelines for the ultrasound assessment of endothelial-dependent flow-mediated vasodilation of the brachial artery: a report of the International Brachial Artery Reactivity Task Force. J Am Coll Cardiol 2002;39(2):257-65.

92. Gokce N., Keaney J.F., Jr., Hunter L.M., et al. Predictive value of noninvasively determined endothelial dysfunction for long-term cardiovascular events in patients with peripheral vascular disease. J Am Coll Cardiol 2003;41(10):1769-75.

93. Neumann T., Kondratieva J., Eggebrecht H., et al. [Coronary heart disease associated with the use of highly active antiretroviral therapy (HAART). A case report and review]. Herz 2005;30 (6):504-9.

94. Neunteufl T., Heher S., Kostner K., et al. Contribution of nicotine to acute endothelial dysfunction in long-term smokers. J Am Coll Cardiol 2002;39(2):251-6.
95. Schachinger V., Britten M.B., Zeiher A.M. Prognostic impact of coronary vasodilator dysfunction on adverse long-term outcome of coronary heart disease. Circulation 2000;101(16):1899-906.

96.Faulx M.D., Wright A.T., Hoit B.D. Detection of endothelial dysfunction with brachial artery ultrasound scanning. Am Heart J 2003; 145(6):943-51.

97.Morgan E.E., Faulx M.D., McElfresh T.A., et al. Validation of echocardiographic methods for assessing left ventricular dysfunction in rats with myocardial infarction. Am J Physiol Heart Circ Physiol 2004;287(5):H2049-H53.

98. Stein J.H., Klein M.A., Bellehumeur J.L., et al. Use of human immunodeficiency virus-1 protease inhibitors is associated with atherogenic lipoprotein changes and endothelial dysfunction. Circulation 2001; 104(3):257-62.

99. Hurlimann D., Chenevard R., Ruschitzka F., et al. Effects of statins on endothelial function and lipid profile in HIV infected persons receiving protease inhibitorcontaining anti-retroviral combination therapy: a randomised double blind crossover trial. Heart 2006;92(1):110-2.

100. Stein J.H., Merwood M.A., Bellehumeur J.L., et al. Effects of pravastatin on lipoproteins and endothelial function in patients receiving human immunodeficiency virus protease inhibitors. Am Heart J 2004;147(4):E18.

101. Charakida M., Donald A.E., Green H., et al. Early structural and functional changes of the vasculature in HIV-infected children: impact of disease and antiretroviral therapy. Circulation 2005;112(1):103-9. 